\title{
Identifying Parabrachial Neurons Selectively Regulating Satiety for Highly Palatable Food in Mice
}

\author{
(D)Erica Rodriguez, David Ryu, Shengli Zhao, Bao-Xia Han, and ${ }^{-}$Fan Wang
}

https://doi.org/10.1523/ENEURO.0252-19.2019

Department of Neurobiology, Duke University Medical Center, Durham, NC 27708

\section{Visual Abstract}

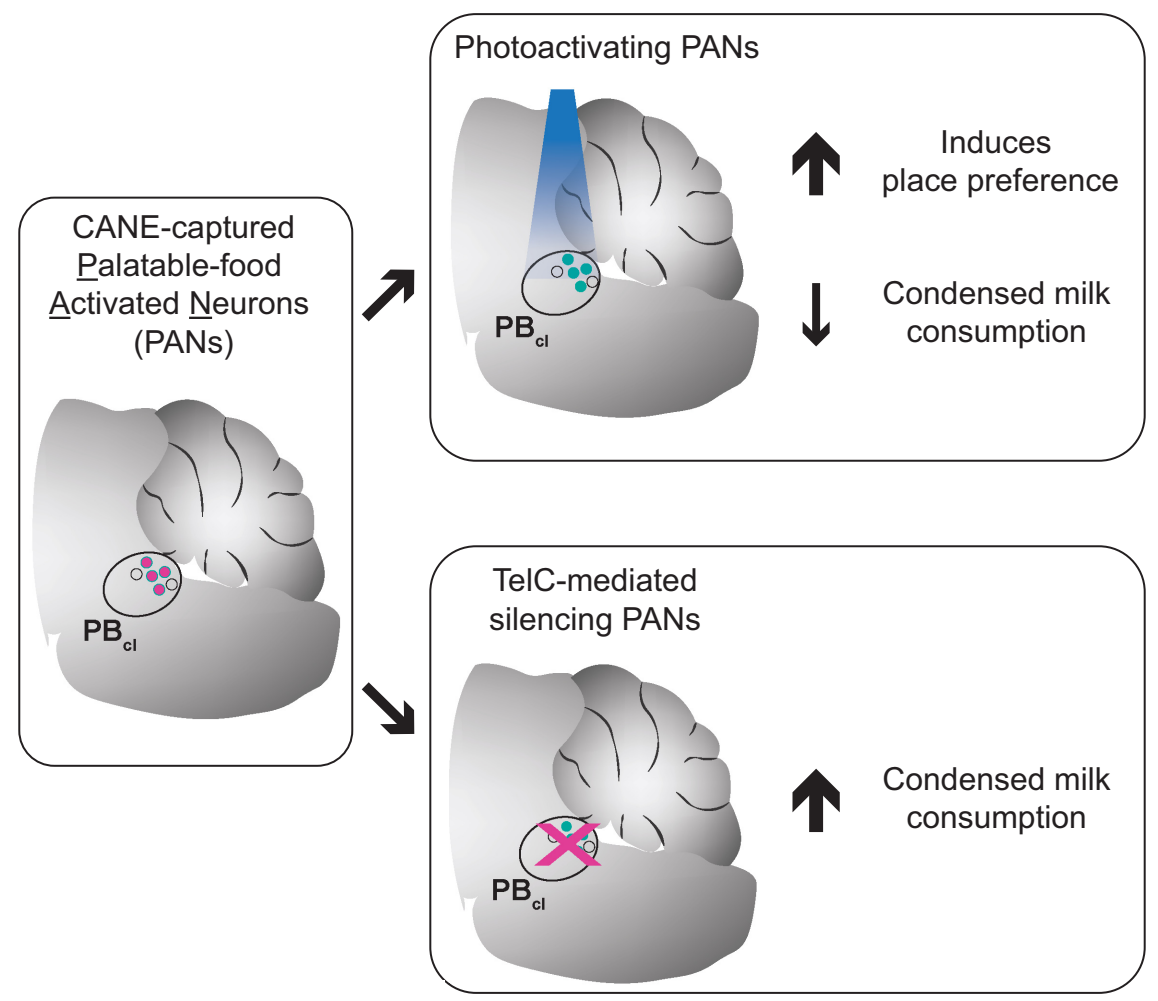

\section{Significance Statement}

The lateral parabrachial nucleus $\left(\mathrm{PB}_{\mathrm{L}}\right)$ is critical for regulating somatic and visceral processes including thermoregulation, taste preference, thirst, and appetite. Recent work on satiety-promoting circuits has implicated the $\mathrm{PB}_{\mathrm{L}}$ as an important node. Previous studies identified the $P B_{\mathrm{L}}{ }^{\mathrm{CGRP}}$ population mediating aversive feeding suppression. However, the identity of the $\mathrm{PB}_{\mathrm{L}}$ population mediating homeostatic satiety is poorly understood. $\mathrm{PB}_{\mathrm{L}}$ 's functional and molecular diversity makes it difficult to separate specific populations critical to regulating specific processes. We address the question by using activity-dependent capturing technology to molecularly identify and selectively activate and inhibit $\mathrm{PB}_{\mathrm{L}}$ neurons activated by consumption of highly palatable food (PANs). We demonstrated that PANs are distinct from $\mathrm{PB}_{\mathrm{L}}{ }^{\mathrm{CGRP}}$ neurons and likely relay appetitive and caloric sufficient satiety signals. 
Food consumption is necessary for organisms to maintain metabolic homeostasis. Both extrinsic and intrinsic processes, relayed via intricate neural circuitry, orchestrate the initiation and termination of food intake. More specifically, there are functionally distinct neural circuits that mediate either homeostatic or hedonic suppression of feeding. Notably, being satiated is a positive feeling whereas food aversion is a negative feeling. While significant progress has been made toward elucidating neural circuitry underlying aversive appetite suppression in mice, the circuitry underlying homeostatic satiety is not fully understood. The lateral parabrachial nucleus $\left(\mathrm{PB}_{\downarrow}\right)$ is known as a node that regulates various sensory and visceral processes. Here, we identified and selectively labeled neurons in the caudal lateral region of $\mathrm{PB}_{\mathrm{L}}\left(\mathrm{PB}_{\mathrm{C}}\right)$ that are activated by consumption of condensed milk, chocolate Ensure, or peanut butter, which we refer to as $\mathrm{PB}_{\mathrm{Cl}}$-palatable-food activated neurons (PANs). Specific optogenetic activation of PANs induced positive place preference but decreased the consumption of high-caloric foods such as condensed milk, whereas silencing these cells significantly increased condensed milk consumption in feeding assays. Thus, the $\mathrm{PB}_{\mathrm{cl}}$ PANs revealed here represent a novel neural substrate regulating caloric-sufficiency mediated satiation.

Key words: brainstem; Fos; novel tools; satiety

\section{Introduction}

Proper regulation of nutrient intake and food consumption is essential for survival and homeostasis in chemotrophic organisms. Feeding is heavily regulated by a multitude of signals coming from exteroceptive processes, such as the availability and taste of food, and interoceptive processes, such as feedback from the gut and adipose tissues (Chambers et al., 2013; Andermann and Lowell, 2017). The signals from these exteroceptive and interoceptive processes are relayed by multiple neural circuits that regulate the initiation and termination of feeding (Sternson and Eiselt, 2017). These neural circuits may undergo maladaptive plasticity in humans suffering from conditions such as anorexia nervosa and obesity, resulting in dysfunctional appetite (Faroogi and O'Rahilly, 2008). Additionally, within these neural circuits, there are a variety of subcircuits which regulate various aspects of feeding, such as hunger, palatable appetite, satiety, and aversive meal termination (Sternson et al., 2016; Sternson and Eiselt, 2017). This complexity makes it challenging to dissect which circuits regulate which aspects of appetite and satiety.

The termination of feeding behavior can result from two separate processes: either due to caloric sufficiency (feeling satiated) or due to receiving aversive anorexigenic signals such as malaise. Significant progress has been

Received June 27, 2019; accepted October 17, 2019; First published October 24, 2019.

The authors declare no competing financial interests.

Author contributions: E.R. and F.W. designed research; E.R. and D.R. performed research; E.R. analyzed data; E.R. and F.W. wrote the paper; S.Z. and B.-X.H. contributed unpublished reagents/analytic tools.

This work was supported by National Institutes of Health Grants DP1 MH103908 (to F.W.) and NIH F31 (DE025197) (to E.R.). E.R. is supported by NIH T32 (MH015144) and by the Helen Hay Whitney Fellowship.

Acknowledgements: We thank Dr. Koji Toda for providing the MATLAB code used in this study. We also thank Dr. Jun Takatoh and Dr. Vincent Prevosto for their assistance and support.

Correspondence should be addressed to Erica Rodriguez at er2934@cumc.columbia.edu.

https://doi.org/10.1523/ENEURO.0252-19.2019

Copyright (C) 2019 Rodriguez et al.

This is an open-access article distributed under the terms of the Creative Commons Attribution 4.0 International license, which permits unrestricted use, distribution and reproduction in any medium provided that the original work is properly attributed. made toward the pathways underlying aversive feeding suppression. Specifically, several studies revealed a group of calcitonin gene-related peptide $\mathrm{CGRP}^{+}$expressing neurons in the lateral parabrachial nucleus $\left(\mathrm{PB}_{\mathrm{L}}{ }^{\mathrm{CGRP}}\right)$ as the key mediator of the aversive signal (Campos et al., 2016, 2018; Carter et al., 2013, 2015). Activation of $\mathrm{PB}_{\mathrm{L}}{ }^{\text {CGRP }}$ neurons induces meal termination, anorexia, and affective nociceptive behavior (Carter et al., 2013; Cai et al., 2014; Han et al., 2015; Campos et al., 2016), whereas silencing these cells prevents anorexia in a cancer model (Campos et al., 2017). These PB ${ }_{L}{ }^{\text {GRPP }}$ cells receive both direct excitatory input from $\mathrm{Th}^{+}$and $\mathrm{Cck}^{+}$ cells in the nucleus of the solitary tract (NTS; Kreisler et al., 2014; D’Agostino et al., 2016; Roman et al., 2016), as well as direct inhibitory input from agouti-related peptide $\left(\mathrm{AGRP}^{+}\right)$expressing neurons in the hypothalamic arcuate nucleus (ARC), which are hunger-activated and promote feeding (Aponte et al., 2011; Krashes et al., 2011; Atasoy et al., 2012; Betley et al., 2013; Burnett et al., 2016; Livneh et al., 2017). The $\mathrm{PB}_{\mathrm{L}}{ }^{\mathrm{CGRP}}$ neurons project to the central amygdala $(\mathrm{CeA})$ and synapse with a subset of protein kinase $\mathrm{c}$ delta $\left(P K C-\delta^{+}\right)$expressing CeA GABAergic neurons to suppress feeding (Cai et al., 2014).

By contrast, our understanding of the circuitry underlying physiologic/homeostatic satiety-mediated meal termination remains incomplete. After food consumption, a cocktail of hormones and neurotransmitters is secreted from enteroendocrine cells residing in the stomach and small intestinal epithelium which signal caloric value and satiety. Vagal sensory afferents detect these signals and transmit the information to NTS (Grill and Hayes, 2009; Chambers et al., 2013; Gribble and Reimann, 2016; Williams et al., 2016; Roman et al., 2017; Kaelberer et al., 2018). Distinct groups of NTS neurons then send this information to multiple brain centers, such as the dorsomotor nucleus of the vagus, the $\mathrm{PB}_{\mathrm{L}}, \mathrm{ARC}$, and the paraventricular hypothalamic nucleus (PVH; Rinaman, 2010; Trapp and Cork, 2015; D'Agostino et al., 2016; Travagli and Anselmi, 2016). Interestingly, melanocortin-4 receptor neurons in $\mathrm{PVH}\left(\mathrm{PVH}^{\mathrm{MC}} 4 \mathrm{R}\right)$ send direct projections onto an unidentified population of neurons in the dorsal portion of $\mathrm{PB}_{\mathrm{L}}$, which appears to be spatially distinct from where $\mathrm{CGRP}^{+}$neurons are located in the ventral portion of $\mathrm{PB}_{\mathrm{L}}$ (Shah et al., 2014; Garfield et al., 2015; Li et al., 2019). Activation of $\mathrm{PVH}^{\mathrm{MC}} 4 \mathrm{R}$ terminals in $\mathrm{PB}_{\mathrm{L}}$ induced satiety, 
while silencing the projections increased food consumption in mice (Garfield et al., 2015; Li et al., 2019). Thus, there appears to be two separate populations in $\mathrm{PB}_{\mathrm{L}}$ : one with an unknown identity that mediates caloric-sufficient satiety versus the $\mathrm{CGRP}^{+}$population that mediates aversive appetite suppression.

In this study, we show that consumption of various highly palatable liquids and food activates a subset of neurons located in the caudal lateral subnucleus of the $\mathrm{PB}_{\mathrm{L}}\left(\mathrm{PB}_{\mathrm{Cl}}\right)$ which are distinct from $\mathrm{PB}_{\mathrm{L}}{ }^{\mathrm{CGRP}}$ neurons. We used the activity-dependent capturing method called CANE (Sakurai et al., 2016; Rodriguez et al., 2017), to identify and characterize $\mathrm{PB}_{\mathrm{cl}}$-palatable-food activated neurons (PANs). We further discovered that activation of these $\mathrm{PB}_{\mathrm{cl}}$ PANs induces reward-like place preference behaviors yet decreases condensed milk consumption, while inhibition of these neurons increases milk consumption.

\section{Materials and Methods}

\section{Animal statement}

All experiments were conducted according to protocols approved by the Duke University Institutional Animal Care and Use Committee.

\section{Animals}

Adult (P30-P60) male and female C57/BL6 mice (The Jackson Laboratory, stock 000664) were used for immunohistochemistry and in situ hybridization. Male and female Fos ${ }^{\text {TVA }}$ mice (Sakurai et al., 2016; The Jackson Laboratory, stock 027831) were used for capturing $\mathrm{PB}_{\mathrm{cl}}$ PANs with the CANE technology, immunohistochemistry, and behavioral experiments for both $\mathrm{ChR} 2$ or TelC experimental and GFP control groups. All mice were housed in a vivarium with normal light/dark cycles in cages with one to five mice. A day before experiments, we singly housed mice. We used two exclusion criteria for our subjects: (1) poor recovery or other health concerns following surgical intervention or (2) missed injection or implantation target, as determined by histologic analysis. Animals were randomly selected from each litter. Random group allocation was maintained throughout the study, within constraints set by availability of in-house, purpose bred lines. Experimenter blinding was sufficient to control for selection bias. Furthermore, behavioral analysis relied on objective, automated measurements.

\section{Viruses}

CANE-LV-Cre [titer, $5 \times 10^{8} \mathrm{ifu} / \mathrm{ml}$ (Addgene plasmid, 86641); CANE-LV envelope (Addgene plasmid, 86666)] viruses were produced and packaged using HEK293T cells by co-transfecting a plasmid encoding the EnvA ${ }^{\mathrm{M} 21}$ VSVG (CANE-LV envelope) fusion envelope protein, the pLenti-hSyn-Cre-WPRE plasmid, and the psPAX2 plasmid into the cells. The CANE-LV envelope has three (R213A, R223A, R224A) mutations in the extracellular domain of the EnvA protein (Sakurai et al., 2016). AAVCBA-Flex-ChR2(H134R)-mCherry (Atasoy et al., 2008; Addgene plasmid, 18916) and AAV-EF1 $\alpha$-flex-ChR2(H134R)eYFP (Karl Deisseroth; Addgene plasmid, 20298) was purchased from the University of Pennsylvania Vector
Core or from Addgene. AAV-CAG-flex-GFP was purchased from the University of North Carolina Gene Therapy Department. AAV-hSyn-Flex-TeLC-P2A-eGFP was produced and packaged using HEK293T cells by cotransfecting the AAV serotype plasmid AAV8, pAAVhSyn-Flex,TeNT-P2A-GFP plasmid, and pAd.DELTA F6 plasmid into the cells (Zhang et al., 2015).

\section{Surgery}

Animals were anesthetized with isoflurane in a stereotaxic frame (David Kopf Instruments) and small craniotomies were made over the target area. To target the caudal-lateral region of $\mathrm{PB}_{\mathrm{L}}$, mice were mounted in the stereotaxic frame at an angle such that lambda was $\sim 180$ $\mu \mathrm{m}$ ventral to bregma (in practice, 140-240 $\mu \mathrm{m}$ ). The stereotaxic coordinates of virus injection and custommade optic fiber (200- $\mu \mathrm{m}$ core diameter, Thorlabs) were $\mathrm{AP}-4.25 \pm 0.15 \mathrm{~mm}, \mathrm{ML} 1.35 \pm 0.15 \mathrm{~mm}$, and DV -3.1 $\pm 0.1 \mathrm{~mm}$. The thin glass capillary was slowly lowered to the target site to minimize the brain injury. Virus was delivered into the target site at a flow rate of $100 \mathrm{nl} / \mathrm{min}$ using a pulled thin glass capillary (Warner Instruments) connected to an UltraMicroPump controlled by a SYSMicro4 Controller 15 (World Precision Instruments).

The injected viruses and the waiting period for viral transgene expression for the different experiments are. For experiments in Figure 1, CANE-LV-Cre $(500 \mathrm{nl})$ together with AAV-CAG-flex-GFP (300 nl), waiting >10 d. For experiments in Figure 2, CANE-LV-Cre $(500 \mathrm{nl})$ together with AAV-CAG-flex-GFP (300 nl), AAV-CBA-FlexChR2(H134R)-mCherry or AAV-EF1 $\alpha$-DIO-hChR2-eYFP (300 nl), waiting six to eight weeks. For experiments in Figure 3, CANE-LV-Cre $(500 \mathrm{nl})$ together with AAV-CAGflex-GFP (300 nl) or AAV-hSyn-Flex-TeLC-P2A-eGFP (300 $\mathrm{nl})$, waiting $7 \mathrm{~d}$.

\section{Immunohistochemistry}

All mice were deeply anesthetized with isoflurane, and then transcardially perfused with ice-cold $4 \%$ paraformaldehyde in $0.1 \mathrm{M}$ phosphate buffer, $\mathrm{pH} 7.4$ (4\% PFA). Dissected brain samples were then postfixed overnight in $4 \%$ PFA at $4^{\circ} \mathrm{C}$, cryoprotected in a $20 \%$ sucrose solution in PBS at $4^{\circ} \mathrm{C}$, frozen in Tissue-Tek O.C.T. compound (Sakura, 25608-930) and stored at $-80^{\circ} \mathrm{C}$ until sectioning. All coronal brain sections were sliced at $60-80 \mu \mathrm{m}$. The serial brain sections were collected in a 24-well plate and washed with PBS three times. The sections were blocked with $2 \%$ bovine serum albumin (BSA) in PBS with $0.3 \%$ Triton X-100 (blocking solution) at room temperature for $1 \mathrm{~h}$. The sections were treated with primary antibody in blocking solution at $4^{\circ} \mathrm{C}$. for overnight. The sections were washed three times followed by secondary antibody treatment at $4^{\circ} \mathrm{C}$ for $2 \mathrm{~h}$. Sections were counter-stained with NeuroTrace fluorescent Nissl stain (fluorescent Nissl stain; Invitrogen, N-21479) or 4',6-diamidino-2-phenylindole (DAPI; Sigma, D9564). After this incubation, sections were washed and mounted. The primary antibodies used in this study are: goat anti-Fos (Santa Cruz Biotechnology, sc52-g, 1:300), rabbit anti-CGRP (Röhn, 2011; Millipore, AB15360, 1:1000), sheep anti-FoxP2 (Geerling et al., 2011; R\&D Systems, AF5647, 1:5000), rabbit anti-Th (Millipore, MAB318, 
A
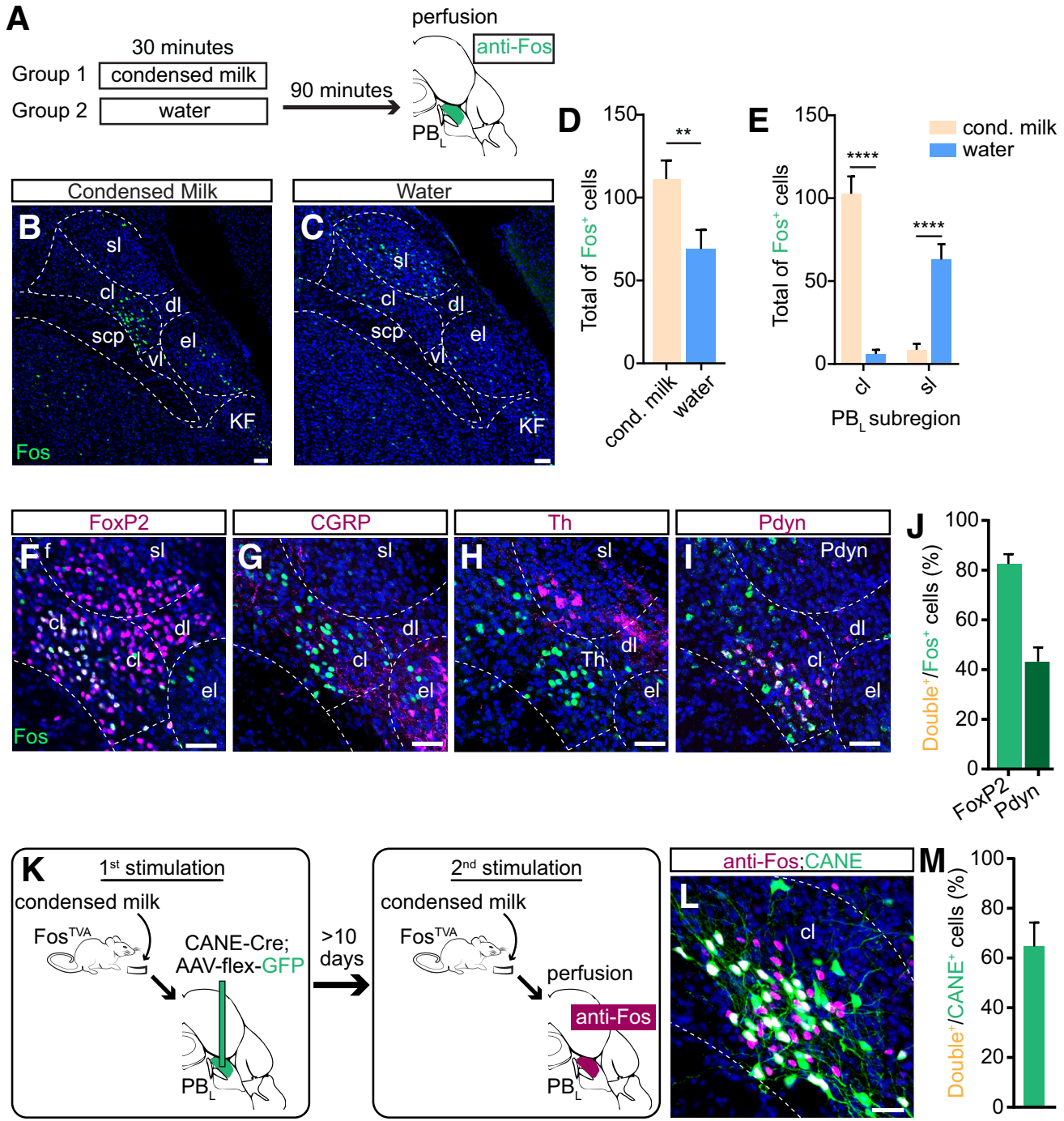

Figure 1. $\mathrm{PB}_{\mathrm{cl}}$ neurons are activated by condensed milk consumption and are molecularly distinct from $\mathrm{CGRP}^{+}$neurons. $\boldsymbol{A}_{\text {, }}$ Schematic illustration of Fos induction protocol. Ninety minutes after mouse consumed condensed milk or water ad libitum for 30 min, brainstem slices containing $\mathrm{PB}_{\mathrm{L}}$ were stained for Fos expression. $\boldsymbol{B}, \boldsymbol{C}$, Representative images of Fos ${ }^{+}$neurons in $\mathrm{PB}_{\mathrm{L}}$ after $(\boldsymbol{B})$ condensed milk consumption and $(\boldsymbol{C})$ water consumption. For representative images of $\mathrm{Fos}^{+}$neurons in $\mathrm{PB}_{\mathrm{L}}$ after consumption of other palatable liquid/food diets, see Extended Data Figure 1-1A-E. Small white dashed circles indicate subregions of $\mathrm{PB}_{\mathrm{L}}$, including sl (superior lateral subnucleus), $\mathrm{cl}$ (caudal lateral subnucleus), dl (dorsal lateral subnucleus), el (external lateral subnucleus), vl (ventral lateral subnucleus), scp (superior cerebellar peduncles), KF (Koelliker-Fuse subnucleus). Blue, DAPI stain. Scale bars, $50 \mu \mathrm{m}$. D, Total number of $\mathrm{Fos}^{+}$neurons in $\mathrm{PB}_{\mathrm{L}}$ of mice that consumed condensed milk (beige, $n=10$ mice) and water (blue, $n=7$ mice; two-tailed unpaired Student's $t$ test; $\left.* * p=0.007 ; t_{(15)}=3.118\right)$. Data are mean \pm SEM. $\boldsymbol{E}$, Numbers of Fos ${ }^{+}$neurons in $\mathrm{PB}_{\mathrm{cl}}$ and $\mathrm{PB}_{\mathrm{sl}}$ of mice that consumed condensed milk (beige, $n=10$ mice) and water (blue, $n=7$ mice; two-way ANOVA; $\mathrm{PB}_{\mathrm{cl}}: * * * * p<0.0001 ; \mathrm{PB}_{\mathrm{sl}}: * * * * p$ $\left.<0.0001 ; F_{(1,30)}=116.7\right)$. Data are mean \pm SEM. $\boldsymbol{F}-\boldsymbol{I}$, Staining of neurons activated by condensed milk consumption (anti-Fos, green)

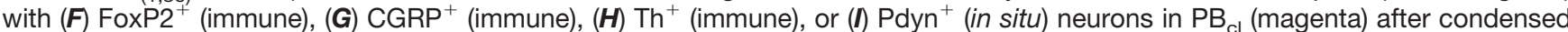
milk consumption. $\boldsymbol{J}$, Quantification of co-expression of $\mathrm{Fos}^{+}$neurons and FoxP2 ${ }^{+}$and $\mathrm{Pdyn}^{+}$neurons. Data are mean $\pm \mathrm{SEM}$. $\boldsymbol{K}$, Schematic illustration of strategy to express GFP in $\mathrm{PB}_{\mathrm{L}}$ neurons activated by condensed milk consumption (PANs) in Fos ${ }^{\text {TVA }}$ mice using CANE. For representative image and quantification of co-expression of Fos ${ }^{+}$neurons and $\mathrm{Pdyn}^{+}$neurons in $\mathrm{PB}_{\mathrm{cl}}$ after chocolate Ensure consumption, see Extended Data Figure 1-1F-H. $L$, The CANE method was used to capture $\mathrm{PB}_{\mathrm{Cl}}$ neurons activated by condensed milk consumption (green), and $10 \mathrm{~d}$ later, Fos was re-induced in $\mathrm{PB}_{\mathrm{cl}}$ by a second bout of condensed milk consumption (magenta). Blue, DAPI. Scale bar, $20 \mu \mathrm{m}$. $\boldsymbol{M}$, The percentage of $\mathrm{Fos}^{+}$neurons among CANE ${ }^{+}$neurons in $\mathrm{PB}_{\mathrm{cl}}$. Data are mean $\pm \mathrm{SEM}$

1:1000). The secondary antibodies are: Alexa Fluor 488 donkey anti-goat (Jackson ImmunoResearch, 705-545-147, 1:1000), Cy3 donkey anti-goat (Jackson ImmunoResearch, 705-165-147, 1:1000), and Cy3 donkey anti-rabbit (Jackson ImmunoResearch, 711-165-152, 1:1000).

\section{Floating section in situ hybridization}

Floating section in situ hybridization was performed following a previously described protocol (Stanek et al., 2016; Bellavance et al., 2017). All mice were deeply anesthetized with isoflurane, and then transcardially perfused 

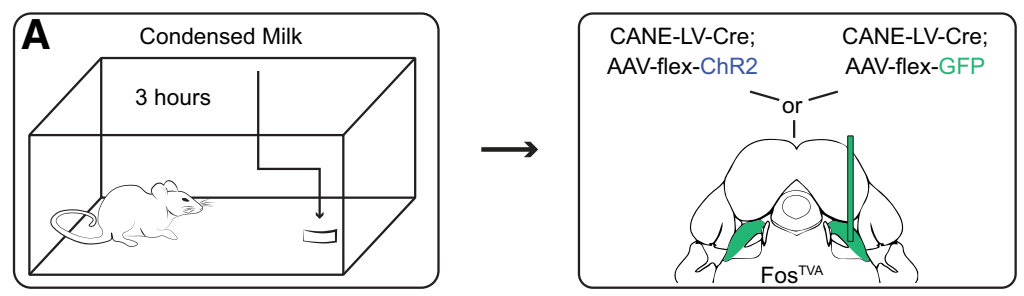

B Real-time place preference

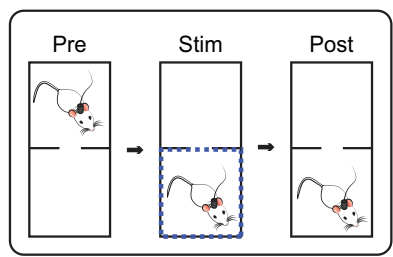

E

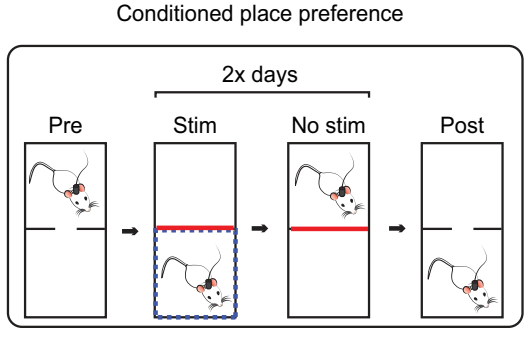

C

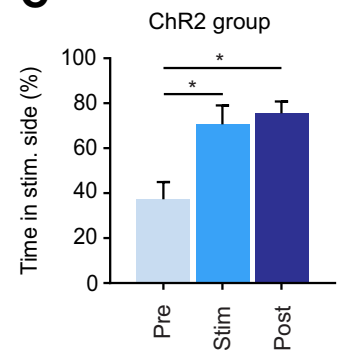

F

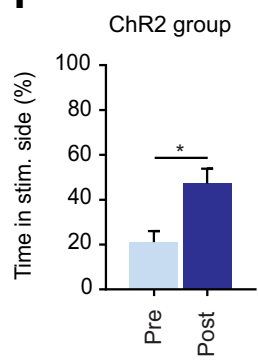

D

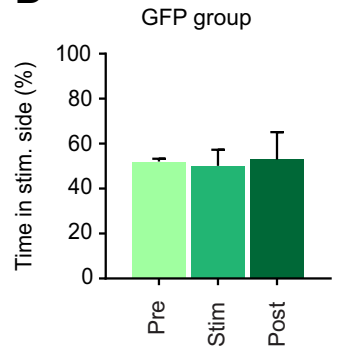

H Food intake assay

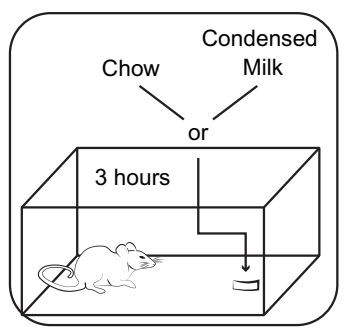

No Light or Light
I

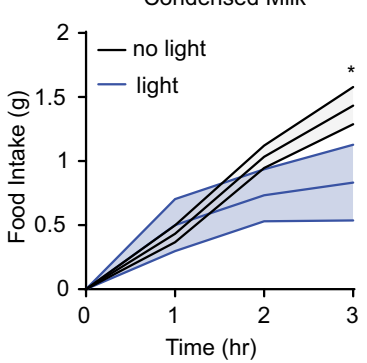

G

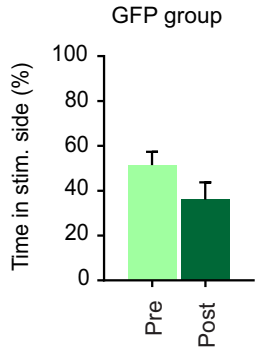

Figure 2. Optogenetic activation of $\mathrm{PB}_{\mathrm{Cl}} \mathrm{PANs}$ induces place preference and decreases condensed milk consumption. $\boldsymbol{A}$, Schematic illustration of strategy to selectively express ChR2 or GFP in $\mathrm{PB}_{\mathrm{Cl}}$ PANs in Fos ${ }^{\text {TVA }}$ mice using CANE. $\boldsymbol{B}$, Schematic illustration of RTPP test. $\boldsymbol{C}$, Quantification of time the PAN-ChR2 group spent in preferred chamber before, during, and after optogenetic stimulation ( $n$ $=6$ mice; one-way repeated measures ANOVA; $\left.* p=0.01 ; * p=0.04 ; p>0.99 ; F_{(1.46,7.29)}=9.22\right)$. Data are mean \pm SEM. $\boldsymbol{D}$, Quantification of time the PAN-GFP group spent in preferred chamber before, during, and after optogenetic stimulation $(n=5$ mice; one-way repeated measures ANOVA; $\left.p>0.99 ; p>0.99 ; p>0.99 ; F_{(1.42,5.69)}=0.05\right)$. Data are mean \pm SEM. E, Schematic illustration of CPP test. $\boldsymbol{F}$, Quantification of time the PAN-ChR2 group spent in preferred chamber before and after $2 \mathrm{~d}$ of optogenetic stimulation $\left(n=8\right.$ mice; two-tailed paired Student's $t$ test; $\left.* p=0.02 ; t_{(7)}=3.05\right)$ Data are mean \pm SEM. G, Quantification of time the PAN-GFP group spent in preferred chamber before and after $2 \mathrm{~d}$ of optogenetic stimulation $(n=5$ mice; two-tailed paired Student's $t$ test; $p$ $\left.=0.19 ; t_{(4)}=1.57\right)$ Data are mean \pm SEM. $\boldsymbol{H}$, Schematic illustration of liquid/food intake assay. $\boldsymbol{I}$, Measured amount of condensed milk consumed at $1 \mathrm{~h}$ ( $n=6$ mice), $2 \mathrm{~h}$ ( $n=3$ mice), and $3 \mathrm{~h}(n=3$ mice) after condensed milk presentation with and without optogenetic stimulation ( $p>0.99 ; p=0.37 ; * p=0.01$; two-way repeated measures ANOVA; $\left.F_{(3,14)}=4.38\right)$. Data are mean \pm SEM. $\boldsymbol{J}$, Measured amount of regular chow consumed at $1 \mathrm{~h}(n=6$ mice), $2 \mathrm{~h}$ ( $n=3$ mice), and $3 \mathrm{~h}(n=3$ mice) after chow presentation with and without optogenetic stimulation $\left(p>0.99 ; p=0.98 ; p=0.92\right.$; two-way repeated measures ANOVA; $\left.F_{(3,14)}=0.93\right)$. Data are mean \pm SEM.

with ice-cold 4\% PFA in $0.1 \mathrm{M}$ phosphate buffer, $\mathrm{pH} 7.4$. Dissected brain samples were then postfixed overnight in $4 \%$ PFA at $4^{\circ} \mathrm{C}$, cryoprotected in a $20 \%$ sucrose solution in PBS in DEPC (Sigma-Aldrich, D5758) treated double- deionized water at $4^{\circ} \mathrm{C}$, frozen in Tissue-Tek O.C.T. Compound and stored at $-80^{\circ} \mathrm{C}$ until sectioning. For each mouse, $60-\mu \mathrm{m}$ sections containing the $\mathrm{PB}_{\mathrm{L}}$ were collected with a cryostat at $-20^{\circ} \mathrm{C}$ and resuspended in $4 \%$ 

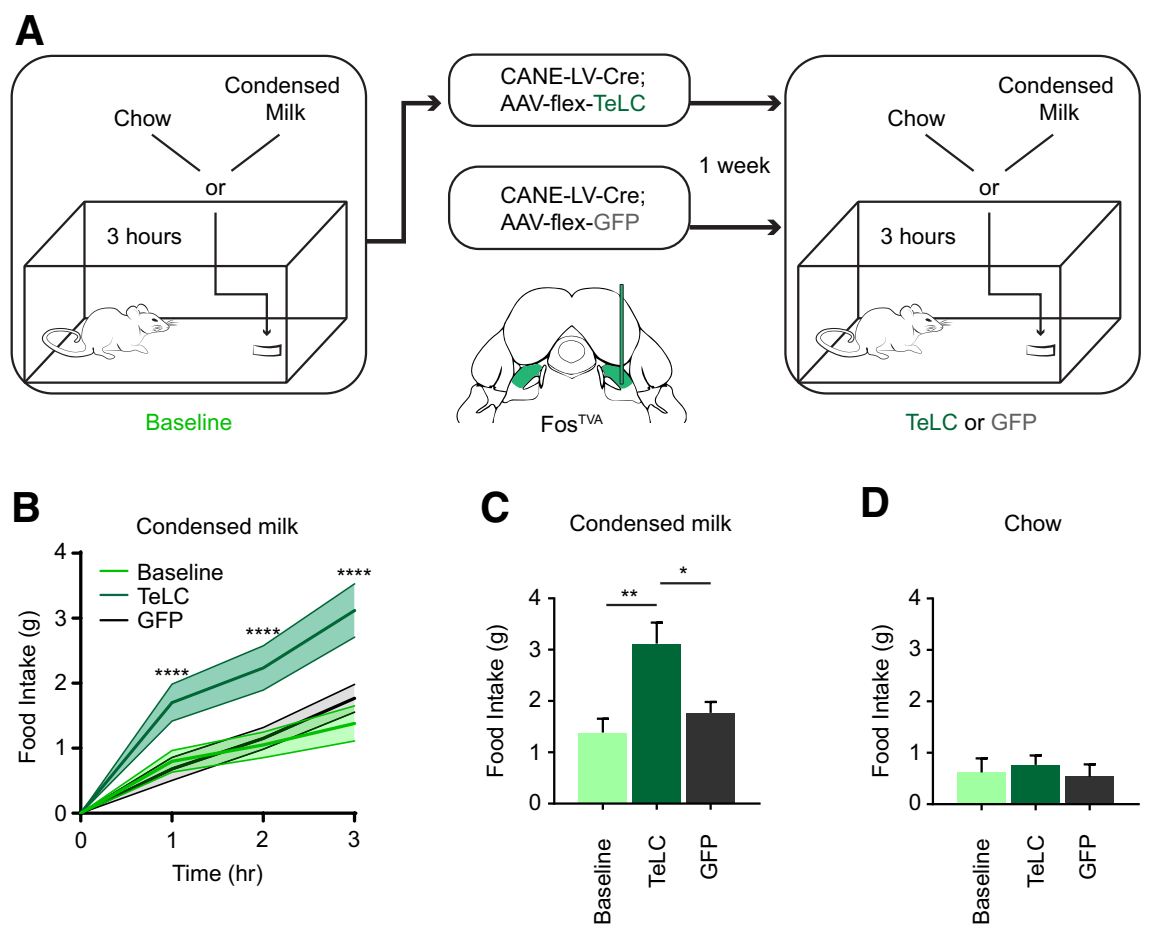

Figure 3. TeLC mediated silencing of $\mathrm{PB}_{\mathrm{Cl}}$ PANs increases condensed milk consumption. $\boldsymbol{A}$, Schematic illustration of the liquid/food intake assay before (baseline) and $7 \mathrm{~d}$ after selectively expressing TeLC or GFP in PB ${ }_{C l}$ PANs in Fos ${ }^{\text {TVA }}$ mice using CANE. B, Measured amount of condensed milk consumed after 1, 2, and $3 \mathrm{~h}$ in PAN-TeLC group before (baseline) and after TeLC expression, and in a control PAN-GFP group ( $n=6$ mice per group; hr 1: ****p $<0.0001$; hr 2: ***** $p<0.0001$; hr 3: *****p $<0.0001$; two-way repeated measures ANOVA; $\left.F_{(3,15)}=62.19\right)$. Data are mean \pm SEM. $C$, Total amount of condensed milk consumed after $3 \mathrm{~h}(n=6 \mathrm{mice}$ per group; baseline compared to TeLC: $* * p=0.004$; baseline compared to GFP: $p>0.99$; TeLC compared to GFP: $* p=0.02$; one-way ANOVA; $\left.F_{(2,15)}=8.61\right)$. Data are mean \pm SEM. $D$, Amount of regular chow consumed $3 \mathrm{~h}$ after chow presentation $(n=6 \mathrm{mice}$ per group; baseline compared to TeLC: $p>0.99$; baseline to GFP: $p>0.99$; TeLC to GFP: $p>0.99$; one-way ANOVA; $\left.F_{(2,15)}=0.25\right)$. Data are mean \pm SEM.

PFA. Samples were rinsed with three times with PBS in DEPC water (DEPC PBS), washed with $0.3 \%$ Triton X-100 in DEPC PBS, treated with $5 \mu \mathrm{g} / \mathrm{ml}$ protinease $\mathrm{K}$ in DEPC PBS, acetylated using a solution of 0.465-g TEA, 28- $\mu 10$ $\mathrm{N} \mathrm{NaOH}, 25-\mathrm{ml}$ DEPC water, and 62.6- $\mu$ l acetic anhydride. Samples were incubated for $1 \mathrm{~h}$ at $60^{\circ} \mathrm{C}$ in a prehybridization buffer solution containing $0.2 \times \mathrm{SSC}$, $10 \%$ blocking reagent (Sigma-Aldrich), 50\% formamide, $2 \% \mathrm{~N}$-lauroylsarcosine (NLS), $10 \%$ SDS for $60 \mathrm{~min}$. This was followed by hybridization of fluorescein isothiocyanate-labeled Fos and digoxigenin-labeled prodynorphin probes which were prepared by amplifying CDNA fragments of Fos and prodynorphin by PCR with the antisense primers containing the T7 promoter sequence. In vitro transcription was then performed from the PCR-amplified template using T7 RNA polymerase (Roche, 10881767001) for the synthesis of the antisense probes (Sakurai et al., 2016). Samples were incubated with probes overnight in hybridization buffer at $60^{\circ} \mathrm{C}$. The following day, samples were washed in prehybridization buffer at room temperature. Samples were incubated at room temperature in a $10 \%$ blocking solution in TBST, followed by application of 1st primary antibody (antiDIG-AP 1:3500, Roche, 11093274910 ) overnight at $4^{\circ} \mathrm{C}$. The following day, samples were washed with TBST, followed by $100 \mathrm{~mm}$ Tris- $\mathrm{HCl}, \mathrm{pH} 8.0$ and hybridization signals for prodynorphin were visualized using FastRed (Sigma-
Aldrich, F4648) for $90 \mathrm{~min}$. This was followed by application of 2 nd primary antibody (POD anti-FITC 1:500, Roche 1426346910) at RT for $1 \mathrm{~h}$, and hybridization signals for Fos were visualized using FITC-TSA (Sigma-Aldrich, F4648) for $10 \mathrm{~min}$. After one wash in PBS-DAPI (1:5000) for 5 min and two washes in buffer solution, sections were mounted on glass slides.

\section{Image acquisition and quantification}

Samples were imaged using a Zeiss 700 laser scanning confocal microscope. In situ samples were imaged at $20 \times$ resolution at three $z$-positions. All $z$-positions for each slice were merged into a single image in Adobe Photoshop CS6 for quantification. All other samples were imaged at $10 \times$ resolution. The captured neurons and Fos expressing neurons in all immunohistochemistry and in situ hybridization experiments were manually counted, and percentages were calculated within each animal before averaging percentages across animals.

\section{Behavioral experiments for Fos immunostaining}

Adult male and female C57/BL6 mice at ages more than six weeks were singly housed at least $1 \mathrm{~d}$ and water restricted overnight before receiving either an appetitive or neutral liquid, or food restricted overnight before receiving peanut butter. For visualizing Fos expression induced by highly-palatable liquid/food consumption, mice 
were given diluted condensed milk (Nestle Carnation), milk chocolate nutrition shake (Ensure Plus), peanut butter (Jif To Go creamy natural peanut butter), $146 \mathrm{mM}$ sucrose (Calbiochem, 8510), $1 \mathrm{mM}$ sucralose (SigmaAldrich, 90984), or water in their home cage for $30 \mathrm{~min}$. Ninety minutes later, the animals were perfused as described in the method for immunostaining above. The nutritional composition of $1 \mathrm{ml}$ (two calories) of 50:50 condensed milk is: 0.09 -g total fat $(0.04-\mathrm{g}$ saturated fat; $21 \%$ of calories), $0.65 \mathrm{mg}$ sodium, $0.37 \mathrm{~g}$ total carbohydrates (0.37-g sugars; $67 \%$ of calories) $0.05-\mathrm{g}$ total protein $(12 \%$ of calories). The nutritional composition of $1 \mathrm{ml}$ (one calorie) of chocolate ensure is: $0.04-g$ total fat (0.01-g saturated fat, $0.02-\mathrm{g}$ polyunsaturated fat, 0.02 monounsaturated fat, $0.04-\mathrm{mg}$ cholesterol; $28 \%$ of calories), 0.9-mg sodium, 2.41-mg potassium, 0.22-g total carbohydrates ( $<0.01$-g dietary fiber, 0.09 -g sugars; $57 \%$ of calories), $0.05-\mathrm{g}$ protein (15\% of calories). The nutritional composition of $1 \mathrm{~g}$ (5.81 calories) of peanut butter is: $0.47-\mathrm{g}$ total fat $(0.1-\mathrm{g}$ saturated fat; $15 \%$ of calories), $2.44-\mathrm{mg}$ sodium, $0.26-\mathrm{g}$ total carbohydrates $(0.07-\mathrm{g}$ dietary fiber, $0.12-g$ sugars; $17 \%$ of calories), $0.23-g$ protein (68\% of calories). The nutritional composition of $1 \mathrm{ml}(0.2$ calories) of $146 \mathrm{mM}(5 \%)$ sucrose in water is: $0.05-\mathrm{g}$ total carbohydrates $(0.05-\mathrm{g}$ sugars; $100 \%$ of calories). The nutritional composition of $1 \mathrm{ml}$ ( 0.1 calories) of $1 \mathrm{mM}$ $(0.04 \%)$ sucralose in water is: $0.04-\mathrm{g}$ total carbohydrates (0.03-g sugars; $100 \%$ of calories).

\section{Behavioral experiments for capturing $\mathrm{PB}_{\mathrm{cl}}$ PANs with CANE virus}

The CANE capturing method is as follows (Sakurai et al., 2016). In Fos ${ }^{\text {TVA }}$ mice, activated neurons transiently express Fos which induces expression of a destabilized TVA (dsTVA) receptor. Lentivirus pseudotyped with an engineered mutated envelope protein (CANE envelope) specifically binds cells expressing high-level TVA receptor, which are strongly $\mathrm{Fos}^{+}$neurons. In this way, CANE viruses selectively infect $\mathrm{Fos}^{+}$neurons and deliver desired transgenes to be expressed in $\mathrm{Fos}^{+}$neurons.

Here, adult male and female Fos ${ }^{\mathrm{TVA}}$ mice at ages more than six weeks were singly housed for at least $1 \mathrm{~d}$ and water restricted overnight and were given diluted condensed milk in their home cage for $30 \mathrm{~min}$; 60-90 min later, mice were anesthetized and underwent stereotaxic surgery for CANE-virus injection.

\section{Optogenetic activation of CANE-captured PB $_{c 1}$ PANs in a real-time place preference (RTPP) test and liquid/food intake assay}

Channelrhodopsin $\left(\mathrm{ChR}^{+}\right)$or control $\left(\mathrm{GFP}^{+}\right)$protein was expressed in CANE-Cre ${ }^{+} \mathrm{PB}_{\mathrm{Cl}}$ PANs by injection of either AAV-CBA-Flex-ChR2(H134R)-mCherry, AAV-EF1 $\alpha$ DIO-hChR2-eYFP or AAV-CAG-Flex-GFP in adult Fos ${ }^{\text {TVA }}$ mice (as described above). Three weeks later, virus injected mice were implanted with custom made optic fibers which were placed above $\mathrm{PB}_{\mathrm{cl}}$ on both sides and fixed on the skull with dental cement (Parkell). One week later, the animals were subjected to a two-chamber RTPP test in light cycle, using a modified method described in previous studies (Stamatakis and Stuber, 2012; Jennings et al., 2013). The custom-made behavior chamber is 50.1 $\times 27.7 \times 31.2 \mathrm{~cm}(\mathrm{~W} \times \mathrm{L} \times \mathrm{H})$, made with clear acrylic Plexiglas that had distinct stripe patterns in each chamber. For optogenetic stimulation, laser is delivered through patch cables attached to the implanted optic fiber. The RTPP test is as follows. The mouse is placed in the center of the box and allowed to explore both chambers without light stimulation (prestimulation) for $10 \mathrm{~min}$. Generally, after exploration, the mouse shows a small preference for one of the two chambers. Subsequently, blue light stimulation $(20 \mathrm{~Hz}, 20-\mathrm{ms}$ pulse width, $\sim 3.5 \mathrm{~mW})$ is delivered whenever the mouse enters or stays in the non-preferred chamber, and light is turned off when the mouse moves to the other chamber (stimulation phase, total $10 \mathrm{~min}$ ). Finally, the mouse can freely explore both chambers without blue light stimulation (poststimulation) for $10 \mathrm{~min}$. We recorded behavioral data via a webcam (Logitech webcamera, PN 960-000764) interfaced with Bonsai software (Lopes et al., 2015). Real-time laser stimulation was controlled by Bonsai software through Arduino with a custom-made Arduino sketch (Arduino UNO, A00073).

After one week, the same group of mice were subjected to another behavioral test, where animals were subjected to a two-chamber classic conditioned place preference (CPP) test in same behavior chamber used for RTPP. The mouse is first habituated to the chamber on day 1 . On day 2 , the mouse is placed in the center of the box and allowed to explore both chambers without light stimulation (prestimulation) for $10 \mathrm{~min}$. Generally, after exploration, the mouse shows a small preference for one of the two chambers. In the following $2 \mathrm{~d}$ (day 3 and day 4), the mouse is closed off in the preferred chamber with no stimulation for $30 \mathrm{~min}$ in the morning, and then closed off in the non-preferred chamber with blue light stimulation ( $20 \mathrm{~Hz}, 20-\mathrm{ms}$ pulse width, $\sim 3.5 \mathrm{~mW}$ ) for $30 \mathrm{~min}$ in the afternoon. On the final day (day 5), the mouse can explore both chambers without blue light stimulation (poststimulation) for $10 \mathrm{~min}$, and their behaviors are recorded and analyzed.

After one week, the $\mathrm{ChR} 2^{+}$group underwent a liquid/ food intake assay in their home cage within 6-9 P.M. (normal feeding cycle), using a modified method as previously described (Garfield et al., 2015; Fenselau et al., 2017; Li et al., 2019). The liquid/food intake assay is as follows: Mice were given a measured amount of diluted condensed milk or regular mouse chow for $3 \mathrm{~h}$ with optogenetic blue light stimulation (5 $\mathrm{s}$ on and $1 \mathrm{~s}$ off, 20 -ms pulses, $20 \mathrm{~Hz}, \sim 3.5 \mathrm{~mW}$ ). The order of the liquid or food was randomized among the groups. The amount of liquid or food ingested was measured as the difference between the final measurement and the initial measurement. After completion of the photostimulation experiments, mice were perfused, and the locations of optic fiber tips were identified.

\section{Genetic silencing of CANE-captured PB $_{\mathrm{cl}}$ PANs in a liquid/food intake assay}

Tetanus toxin (TeLC) or control GFP was expressed in CANE-Cre ${ }^{+} \mathrm{PB}_{\mathrm{L}}$-satiety neurons by injection of either AAV-hSyn-Flex-TeLC-P2A-eGFP or AAV-CAG-Flex-GFP 
in adult Fos ${ }^{\text {TVA }}$ mice (as described above). Three days before virus injection (baseline), the experimental group was subjected to the liquid/food intake assay in their home cage from 6-9 P.M. (normal feeding cycle), where they were given a measured amount of diluted condensed milk or regular mouse chow. The order of the liquid or food was randomized among the groups. The amount of diluted condensed milk or water was measured every hour for $3 \mathrm{~h}$. This assay was repeated for both TelC and control groups $8 \mathrm{~d}$ after virus injection (TeLC, control). The amount of liquid or food ingested was measured as the difference between the measurements taken at each hour and the initial measurement. After completion of the silencing experiments, mice were perfused, and viral expression was assessed.

\section{Statistical analysis}

All data are presented as mean \pm SEM. Statistical analysis of data were conducted and graphed using GraphPad Prism 8 (Prism software). Significance was set at $p<0.05$. All data were normally distributed as determined by a Shapiro-Wilk normality test. For Figure $1 D$, unpaired Student's $t$ test was used to compare milk and water groups. For Figure 1E, two-way ANOVA of treatment over brain region was used with a Bonferroni post hoc test to assess differences in Fos expression. For Figure $2 F, G$, paired Student's $t$ tests were used to compare before and after optogenetic stimulation. For Figure $2 C, D$, one-way repeated measures ANOVA of before, during, and after optogenetic-stimulation was used followed by a Bonferroni post hoc test to assess changes in time spent in preferred side. For Figures $2 I, J, 3 B$, twoway repeated measures ANOVA of mouse group and time was used followed by a Bonferroni post hoc test to assess changes in liquid or food intake over time. For Figure $3 C, D$, one-way ANOVA of mouse group over liquid or food intake was used followed by a Bonferroni post hoc test. Relevant values used for statistical analysis are included in the figure legends as follows: ( $t$ test) $t$ subscript degrees of freedom $=t$ statistic; (ANOVA) $F$ subscript betweengroups degrees of freedom, within groups degrees of freedom $=F$ statistic.

\section{Data availability}

The data collected in this study are available from the corresponding author on request.

\section{Results}

\section{Consumption of highly palatable foods activates $\mathrm{PB}_{\mathrm{cl}}$ neurons}

Mice were given access to drink from either a bottle containing water, a non-caloric liquid, or a bottle containing $50 \%$ condensed milk, a high-caloric palatable liquid food, alone, for $30 \mathrm{~min}$ after overnight water restriction, euthanized, and brain sections were immunostained for expression of immediately-early gene Fos as a marker for activated neurons in $\mathrm{PB}_{\mathrm{L}}$ (Fig. 1A). Drinking condensed milk activated neurons in $\mathrm{PB}_{\mathrm{L}}$, resulting in significantly more Fos ${ }^{+}$neurons than drinking water (condensed milk, $116.4 \pm 9.83$, and water, $69 \pm 11.52$ total Fos ${ }^{+}$neurons; $p=0.007 ; n=10,7 ;$ Fig. $1 B, C)$. Furthermore, drinking condensed milk induced robust $\mathrm{Fos}^{+}$expression specifically in $\mathrm{PB}_{\mathrm{cl}}$, whereas drinking water preferentially activated neurons in the superior lateral subnucleus of the $\mathrm{PB}_{\mathrm{L}}\left(\mathrm{PB}_{\mathrm{s}} ; \mathrm{PB}_{\mathrm{cl}}\right.$ : condensed milk $105.3 \pm 8.93$, water $6 \pm$ 2.61 Fos $^{+}$neurons; $p<0.0001 ; n=10,7$; and $\mathrm{PB}_{\mathrm{sl}}$ : condensed milk $11.1 \pm 3.37$, water $63 \pm 9.28 \mathrm{Fos}^{+}$ neurons; $p<0.0001 ; n=10$, 7 ; Fig. $1 B-D$ ). To determine whether $\mathrm{PB}_{\mathrm{cl}}$ neurons were activated by intake of other palatable liquid or food, separate groups of mice were given access to either chocolate Ensure, peanut butter, $146 \mathrm{mM}$ sucrose dissolved in water, or $1 \mathrm{mM}$ sucralose dissolved in water (Extended Data Fig. 1-1A). Drinking chocolate Ensure, another high-caloric palatable liquid, also induced robust Fos ${ }^{+}$expression specifically in $\mathrm{PB}_{\mathrm{cl}}$ (Extended Data Fig. 1-1B). Interestingly, consuming peanut butter, a high-caloric solid food, induced robust Fos ${ }^{+}$ expression in the same $\mathrm{PB}_{\mathrm{Cl}}$ region (Extended Data Fig. 1-1C). In contrast, drinking either sucrose or sucralose, which are low- or non-caloric sweet tastants, preferentially activated neurons in $\mathrm{PB}_{\mathrm{sl}}$, but not in $\mathrm{PB}_{\mathrm{cl}}$ (Extended Data Fig. 1-1D,E). These results are similar to that observed for drinking water. In other words, non-caloric and caloric liquid intakes are regulated by distinct circuits in $\mathrm{PB}_{\mathrm{L}}$, a result consistent with a recent finding Oxtr ${ }^{+} \mathrm{PB}_{\mathrm{L}}$ neurons selectively regulating non-caloric fluid drinking (Ryan et al., 2017). Therefore, we called these $\mathrm{PB}_{\mathrm{cl}}$ neurons palatable-food activated neurons (PANs). Notably, a previous study showed that the satiety-signaling $\mathrm{PVH}^{\mathrm{MC}} 4 \mathrm{R}$ afferents terminate in the $\mathrm{PB}_{\mathrm{cl}}$ region where the PANs are located (Shah et al., 2014; Garfield et al., 2015; Li et al., 2019).

\section{$\mathrm{PB}_{\mathrm{cl}}$ PANs are distinct from CGRP ${ }^{+} \mathrm{PB}_{\mathrm{el}}$ neurons}

Forkhead box protein P2 (FoxP2) transcription factor was previously shown to be primarily expressed in dorsal subregions of $\mathrm{PB}_{\mathrm{L}}$ (Geerling et al., 2011; Gaub et al., 2016). Using two-color immunofluorescence, we found that a majority of $\mathrm{Fos}^{+} \mathrm{PB}_{\mathrm{cl}} \mathrm{PANs}$ expressed FoxP2, but they represented a small fraction of the total FoxP2 ${ }^{+} \mathrm{PB}_{\mathrm{L}}$ cells $\left(83.19 \pm 3.29\right.$ of total $\mathrm{Fos}^{+} \mathrm{PB}_{\mathrm{Cl}}$ PANs were FoxP2 ${ }^{+}$; $n=4$; Fig. $1 F, J)$. We next determined whether $\mathrm{Fos}^{+} \mathrm{PB}_{\mathrm{cl}}$ PANs express CGRP and found that there was no overlap (0 of total Fos ${ }^{+} \mathrm{PB}_{\mathrm{Cl}}$ PANs were $\mathrm{CGRP}^{+} ; n=4$; Fig. 1G). This finding suggests that these Fos ${ }^{+} \mathrm{PB}_{\mathrm{Cl}}$ PANs are likely functionally distinct from anorexigenic $\mathrm{PB}_{\mathrm{L}}{ }^{\mathrm{CGRP}}$ neurons (located in the external lateral part of $\mathrm{PB}_{\mathrm{L}}$ ).

We next consulted the Allen Brain Atlas to find other potential genetic markers enriched in $\mathrm{PB}_{\mathrm{cl}}$ subregion. Two candidate genes were identified: tyrosine hydroxylase $(T h)$, which encodes the enzyme regulating the synthesis of the neurotransmitter dopamine, and prodynorphin $(P d y n)$, which encodes the neuropeptide dynorphin and is previously shown to be expressed in cells implicated in thermo-sensation (Geerling et al., 2011). Using immunohistochemistry, we found that $F_{0 S^{+}} \mathrm{PB}_{\mathrm{cl}}$ PANs do not express Th $\left(0\right.$ of total $\mathrm{Fos}^{+} \mathrm{PB}_{\mathrm{cl}}$ PANs were $\mathrm{Th}^{+} ; n=4$; Fig. $1 H, J)$. Interestingly, using two-color in situ hybridization, we found that $\sim 44 \%$ of $\mathrm{Fos}^{+}$PANs activated by condensed milk consumption and $38 \%$ of $\mathrm{Fos}^{+}$PANs activated by chocolate Ensure consumption were Pdyn ${ }^{+}$ 
$[43.62 \pm 8.16 ; n=3$ (Fig. 1I,J); $38 \pm 5.55 ; n=4$ (Extended Data Fig. 1-1F-H)], suggesting the possibility that dynorphin is released on consumption of highly caloric palatable liquids.

\section{CANE is efficient and selective in activity-dependent capture of PB $_{\mathrm{cl}}$ PANs}

To determine the functional role of $\mathrm{Fos}^{+} \mathrm{PB}_{\mathrm{cl}}$ PANs in liquid and food consummatory behaviors, we needed to label and manipulate these cells specifically. Since we did not identify any molecular markers that are expressed by all PANs and are only expressed in PANs, we therefore used an activity-dependent method called CANE, to virally tag transiently activated neurons in the genetically engineered Fos ${ }^{\text {TVA }}$ mice (Sakurai et al., 2016; Rodriguez et al., 2017). We first determined whether CANE could indeed selectively and efficiently label $\mathrm{PB}_{\mathrm{cl}}$ PANs. In a two-bout experimental paradigm, CANE was used to capture $\mathrm{PB}_{\mathrm{Cl}}$ neurons activated by drinking condensed milk through co-injection of CANE-LV-Cre and AAV-flex-GFP into the $\mathrm{PB}_{\mathrm{cl}}$. Three weeks later, the same animal drank milk again to induce Fos $^{+}$expression and was then anesthetized and killed to obtain samples for immunostaining (Fig. $1 K)$. In the milk-milk condition, $64.66 \pm 4.3 \%(n=5)$ of CANE-captured cells were Fos ${ }^{+}$(Fig. $1 L, M$ ). This indicated that the second condensed milk consumption reactivated many ( $\sim 65 \%)$ of the same cells excited by the first consumption. Thus, CANE is sufficiently specific and efficient to tag PANs.

\section{Optogenetic activation of $\mathrm{PB}_{\mathrm{cl}}$ PANs neurons elicits place preference}

Given that $\mathrm{PB}_{\mathrm{cl}}$ PANs are activated by consuming highcaloric palatable liquids and solid food, we asked whether artificially activating these cells will produce a positive feeling. To test this, we used CANE to express either channelrhodopsin or GFP (control) in $\mathrm{PB}_{\mathrm{cl}}$ PANs, and subjected mice to a modified RTPP assay, which has been used in recent studies to assay affective behavior (Stamatakis and Stuber, 2012; Jennings et al., 2013). Optic fibers were implanted bilaterally above $\mathrm{PB}_{\mathrm{Cl}}$ in either PAN-ChR2 mice $(n=6)$ or PAN-GFP mice ( $n=5$; Fig. $2 A)$. Mice were habituated and placed in a two-chamber arena. Their behaviors were recorded under three conditions: (1) freely exploring with no stimulation for $10 \mathrm{~min}$ (baseline), followed by (2) 10 min of conditioned photoactivation when the mouse is in its non-preferred chamber (stimulation), and followed again by (3) $10 \mathrm{~min}$ without stimulation (poststimulation; Fig. 2B). On photo-stimulation PAN-ChR2 mice spent significantly more time on the stimulated side (pre: $37.31 \pm 7.61 \%$, stim: $70.63 \pm$ $8.38 \%, p=0.01, n=6$; Fig. $2 C$ ). In the poststimulation period, all stimulated mice still showed preference of the chamber in which they received photostimulation (pre: $37.31 \pm 7.61 \%$, post: $75.58 \pm 5.24 \%, p=0.04, n=6$; Fig. 2C). Light illumination had no effect on movement and behavior of the PAN-GFP mice (pre: $52.08 \pm 1.23 \%$; stim: $50.11 \pm 7.19 \%$, post: $52.92 \pm 12.17 \%, p>0.99, n$ $=5$; Fig. $2 D$ ). These results suggest that the optogenetic stimulation of the $\mathrm{PB}_{\mathrm{cl}} \mathrm{PANs}$ caused an appetitive effect, indicating that the neurons likely encode a positive emotional valence.

We further wanted to determine whether optogenetic activation would be sufficient to induce a longer lasting positive memory using the conventional CPP assay. Mice were habituated first by placing them in the two-chamber arena and allowing free exploration. Subsequently, they were subjected to $2 \mathrm{~d}$ of conditioning: mice were paired with photostimulation in the non-preferred chamber for $30 \mathrm{~min}$, and $8 \mathrm{~h}$ later, they were placed in the preferred chamber without light stimulation for $30 \mathrm{~min}$. On the fourth day, they explored the arena freely in the absence of light stimulation for 10 min (poststimulation; Fig. 2E). PAN-ChR2 mice $(n=8)$ spent significantly more time in the chamber where they were photostimulated previously (pre: $21.12 \pm 4.912$, post: $47.27 \pm 6.541, P=0.02$; Fig. $2 F$ ). Light illumination had no effect on the movement and behavior of the control PAN-GFP mice $(n=5$; pre: 51.46 \pm 5.86, post: $36.01 \pm 7.753, p=0.19$; Fig. $2 G$ ). These results suggest that optogenetic activation of $\mathrm{PB}_{\mathrm{cl}} \mathrm{PANs}$ produced a preference memory.

\section{Optogenetic Activation of $\mathrm{PB}_{\mathrm{cl}}$ PANs neurons decreases condensed milk consumption}

Previous studies have shown that activation of $\mathrm{PVH}^{\mathrm{MC}} 4 \mathrm{R}$ afferents in $\mathrm{PB}_{\mathrm{Cl}}$ region induced homeostatic regulated satiety (Garfield et al., 2015; Li et al., 2019). Therefore, we wanted to determine whether activating CANE-captured PANs would also affect liquid and food intake. PAN-ChR2 mice $(n=6)$ underwent a caloric liquid/ food intake assay in their home cage during their normal feeding cycle, where they were given a measured amount of condensed milk or regular mouse chow, which is less palatable, for $3 \mathrm{~h}$ either without (baseline) or with optogenetic stimulation (Fig. 2H; Garfield et al., 2015; Fenselau et al., 2017; Li et al., 2019). At $1 \mathrm{~h}$ after the start of feeding, the amount of condensed milk ingested was not different between the two conditions (with or without light stimulation; $n=6$; no light, $0.43 \pm 0.07$; light, $0.5 \pm 0.2 ; p>$ 0.99; Fig. 2/). However, when measured after $3 \mathrm{~h}$, the total amount of condensed milk ingested in the PAN-activated condition was significantly less $(n=3$; no light, $1.43 \pm$ 0.15 ; light, $0.83 \pm 0.3 ; p=0.01$; Fig. $2 /$ ). Light illumination had no effect on the consumption of regular chow either measured after $1 \mathrm{~h}(n=6$; no light, $0.13 \pm 0.04$; light, 0.17 $\pm 0.09 ; p>0.99$; Fig. 2 J) or after $3 \mathrm{~h}(n=3$; no light, 0.43 \pm 0.2 ; light, $0.43 \pm 0.12 ; p>0.99$; Fig. 2 J). These results suggest that activation of $\mathrm{PB}_{\mathrm{Cl}}$ PANs is sufficient to specifically reduce the consumption of highly caloric and appetitive condensed milk, but not the regular chow, over a long duration. These results complement the previous findings revealing the homeostatic role of activating $\mathrm{PVH}^{\mathrm{MC}} 4 \mathrm{R}-\mathrm{PB}_{\mathrm{Cl}}$ pathway in reduction of liquid/food intake (Shah et al., 2014; Garfield et al., 2015; Li et al., 2019).

\section{TeLC-mediated silencing of PB $_{\mathrm{cl}}$ PANs increases condensed milk consumption}

We next asked whether silencing the PANs would increase caloric liquid or food consumption. We used CANE to express either TeLC or GFP in PB ${ }_{C I}$ PANs. TeLC abolishes synaptic transmission from PANs. PAN-TeLC $(n=$ 
6 ) and PAN-GFP mice $(n=6)$ underwent the liquid/food intake assay in their home cage during their normal feeding cycle before (baseline) and after CANE-mediated expression of TeLC or GFP (Fig. 3A). We observed a steady increase of condensed milk intake occurring 5-7 d after TeLC expression (data not shown). This increase in condensed milk intake plateaued after $7 \mathrm{~d}$. On day 7 , we observed a significant increase in condensed milk intake compared to Baseline, and compared to PAN-GFP mice at $7 \mathrm{~d}$ after GFP expression (hour 1-3: $p<0.0001$; total milk intake: baseline vs TeLC; $p=004$; GFP vs TeLC; $p=$ 0.02 ; Fig. $3 B, C)$. Although we saw momentary body weight gain during the $3-\mathrm{h}$ access to condensed milk, we did not observe an overall increase in body weight $7 \mathrm{~d}$ after TeLC expression (data not shown), and we did not test the animals over long-term on a high-caloric diet. There was no difference in condensed milk intake between PAN-GFP mice and baseline of PAN-TeLC mice before TeLC was expressed (total milk intake: baseline vs GFP; $p>0.99$; Fig. 3B,C). Interestingly, there was no significant difference across all groups in regular chow intake (baseline vs TeLC, $p>0.99$; control vs TeLC, $p>$ 0.99; baseline vs control, $p>0.99$; Fig. $3 D$ ). These results suggested that $\mathrm{PB}_{\mathrm{Cl}} \mathrm{PANs}$ is specifically required for preventing over consumption of a high-caloric palatable diet, while other pathways (see Discussion) are sufficient for signaling satiety from regular food.

\section{Discussion}

Here, we molecularly and functionally characterized an ensemble of neurons located within $\mathrm{PB}_{\mathrm{Cl}}$ that likely relay appetitive and satiating signals after consuming highly caloric liquid and food diets. In previous studies, it was discovered that $\mathrm{PVH}^{\mathrm{MC}} 4 \mathrm{R}$ neurons regulate satiety and prevent over-feeding and consequent obesity (Balthasar et al., 2005). $\mathrm{PVH}^{\mathrm{MC} 4 \mathrm{R}}$ axons innervate $\mathrm{PB}_{\mathrm{Cl}}$ (Shah et al., 2014; Garfield et al., 2015). Optogenetic activation of $\mathrm{PVH}^{\mathrm{MC}} \mathrm{R}-\mathrm{PB}_{\mathrm{Cl}}$ axons reduced food intake and induced positive affective behavior (Garfield et al., 2015). These and other studies have implied that neurons in $\mathrm{PB}_{\mathrm{cl}}$ play a role in homeostatic caloric-dependent satiety in sated states, but the identities of the caloric-dependent satietysignaling neurons in $\mathrm{PB}_{\mathrm{Cl}}$ were unknown (Balthasar et al., 2005; Shah et al., 2014; Garfield et al., 2015; Li et al., 2019). Using a combination of activity-dependent tagging, in vivo optogenetic activation, and TeLC silencing experiments, we uncovered palatable food activated neurons in $\mathrm{PB}_{\mathrm{Cl}}$ that are molecularly and functionally distinct from $\mathrm{CGRP}^{+}$anorexigenic neurons located in $\mathrm{PB}_{\mathrm{el}}$ and spatially and functionally distinct from $\mathrm{Oxtr}^{+}$non-caloric fluid regulating neurons located in $\mathrm{PB}_{\mathrm{sl} / \mathrm{dl}}$ (Campos et al., 2016; Ryan et al., 2017).

A total of $44 \%$ of $\mathrm{PB}_{\mathrm{cl}}$ PANs expressed Pdyn suggesting that a heterogeneous population of PANs work together to regulate satiety of highly caloric food in sated states. Optogenetic activation and TeLC silencing of PANs bidirectionally regulated consumption of condensed milk, a highly caloric liquid diet, but not regular chow. Therefore, it is possible that PANs are a subpopulation of a caloric-dependent satiety regulating ensemble in $\mathrm{PB}_{\mathrm{cl}}$. Further molecular characterization, potentially using RNA sequencing in combination with the CANE strategy, may be required to reveal the full ensemble of caloric-dependent satiety-signaling neurons in $\mathrm{PB}_{\mathrm{cl}}$. This result also demonstrates the selectivity of the CANE method in capturing $\mathrm{PB}_{\mathrm{Cl}}$ neurons activated by consumption of condensed milk. Nevertheless, it has not been determined whether these CANE-captured $\mathrm{PB}_{\mathrm{cl}} \mathrm{PANs}$ neurons are the same $\mathrm{PB}_{\mathrm{cl}}$ population implicated in receiving satiety-related interoceptive information directly from $\mathrm{PVH}^{\mathrm{MC}} 4 \mathrm{R}$ neurons. Based on the anatomic location of PANs and their functional role in caloric-dependent satiety, activity-dependent transsynaptic tracing may reveal that majority of these neurons do receive direct input from caloric-dependent satiety regulating $\mathrm{PVH}^{\mathrm{MC}} 4 \mathrm{R}$ neurons. Thus, future activity-dependent capturing studies are necessary for a detailed analysis and characterization of the $\mathrm{PVH}^{\mathrm{MC} 4 \mathrm{R}}-\mathrm{PB}_{\mathrm{Cl}}$ satiety-regulating pathway.

Our finding that consumption of high caloric liquid and foods preferentially activates $\mathrm{PB}_{\mathrm{cl}}$ neurons that signal satiety maintenance sheds some light on a complex circuit of $P B_{L}$ neurons signaling different facets of liquid and food intake regulation: caloric versus non-caloric, liquid versus food, nutritional composition, sated versus hunger states, and appetitive versus aversive. Recently, multiple parallel $\mathrm{PB}_{\mathrm{L}}$ circuits have been discovered to be critical regulators of satiety. Although the $\mathrm{PVH}^{\mathrm{MC} 4 \mathrm{R}}-\mathrm{PB}_{\mathrm{cl}}$ circuit plays a role in regulating satiety in a sated state, these neurons comprise of $\sim 50 \%$ of $\mathrm{PVH}$ neurons that mediate satiety. Recently, it was shown that the other $\sim 50 \%$ of PVH neurons, which expressed Pdyn and project to the prelocus coeruleus (preLC), similarly regulate satiety in sated states (Li et al., 2019). In parallel, a group of $\mathrm{Oxtr}^{+}$ neurons located in $\mathrm{PB}_{\mathrm{s} / \mathrm{dl}}$ specifically regulate non-caloric fluid intake, but not caloric-dependent satiety (Ryan et al., 2017). Together, some of these distinct $\mathrm{PB}_{\mathrm{L}}$ and preLC circuits (i.e., $\mathrm{Pdyn}^{+}$caloric-signaling neurons and $\mathrm{Oxtr}^{+}$ neurons fluid intake-signaling neurons) may act together for integrated food and fluid intake regulation. Other $P B_{L}$ circuits, however, may act antagonistically with one another in regards to the valence of food intake (i.e., Pdyn ${ }^{+}$ appetitive-signaling neurons and $\mathrm{CGRP}^{+}$malaise-signaling neurons). Further work investigating how much these circuits contribute in working synergistically or antagonistically is critical to understanding $\mathrm{PB}_{\mathrm{L}}$ 's role within the complex fluid/food regulating circuit.

The $\mathrm{PB}_{\mathrm{cl}}$ PANs were identified through Fos expression after condensed milk consumption. Although Fos is a surrogate for elevated neural activity, it lacks temporal resolution and does not give any information about second-to-second neural dynamics. Therefore, it is unclear when $\mathrm{PB}_{\mathrm{cl}}$ neural activity increases during consumption. Future studies can take advantage of the CANE method to express a genetically encoded calcium indicator (such as GCaMP), and use in vivo calcium imaging (Ghosh et al., 2011; Chen et al., 2013) to track the activity of these cells in real-time while the mouse is consuming various liquids or foods (e.g., water, sucrose, condensed milk, chow) in a multitude of contexts and states (e.g., hungry vs sated). These techniques will shed light on the 
population dynamics of $\mathrm{PB}_{\mathrm{cl}}$ cells in appetite/satiety regulation, whether and when the magnitude or firing rate of neural response to appetitive liquid and food consumption changes, and if there are subsets of neurons firing at distinct time points throughout feeding. Overall, the findings in this study further advanced our understanding of the neural circuit regulating satiety mediated termination of feeding. Future studies should take advantage of these $\mathrm{PB}_{\mathrm{cl}}$ PANs to identify their downstream targets and elucidate how signals from PANs are used to control feeding behaviors.

\section{References}

Andermann ML, Lowell BB (2017) Toward a wiring diagram understanding of appetite control. Neuron 95:757-778.

Aponte Y, Atasoy D, Sternson SM (2011) AGRP neurons are sufficient to orchestrate feeding behavior rapidly and without training. Nat Neurosci 14:351-355.

Atasoy D, Aponte Y, Su HH, Sternson SM (2008) A FLEX switch targets channelrhodopsin-2 to multiple cell types for imaging and long-range circuit mapping. J Neurosci 28:7025-7030.

Atasoy D, Betley JN, Su HH, Sternson SM (2012) Deconstruction of a neural circuit for hunger. Nature 488:172-177.

Balthasar N, Dalgaard LT, Lee CE, Yu J, Funahashi H, Williams T, Ferreira M, Tang V, McGovern RA, Kenny CD, Christiansen LM, Edelstein E, Choi B, Boss O, Aschkenasi C, Zhang CY, Mountjoy K, Kishi T, Elmquist JK, Lowell BB (2005) Divergence of melanocortin pathways in the control of food intake and energy expenditure. Cell 123:493-505.

Bellavance MA, Takatoh J, Lu J, Demers M, Kleinfeld D, Wang F, Deschênes $M$ (2017) Parallel inhibitory and excitatory trigeminofacial feedback circuitry for reflexive vibrissa movement. Neuron 95:722-723.

Betley JN, Cao ZFH, Ritola KD, Sternson SM (2013) Parallel, redundant circuit organization for homeostatic control of feeding behavior. Cell 155:1337-1350.

Burnett CJ, Li C, Webber E, Tsaousidou E, Xue SY, Brüning JC, Krashes MJ (2016) Hunger-driven motivational state competition. Neuron 92:187-201.

Cai H, Haubensak W, Anthony TE, Anderson DJ (2014) Central amygdala PKC- $\delta+$ neurons mediate the influence of multiple anorexigenic signals. Nat Neurosci 17:1240-1248.

Campos CA, Bowen AJ, Schwartz MW, Palmiter RD (2016) Parabrachial CGRP neurons control meal termination. Cell Metab 23:811820.

Campos CA, Bowen AJ, Han S, Wisse BE, Palmiter RD, Schwartz MW (2017) Cancer-induced anorexia and malaise are mediated by CGRP neurons in the parabrachial nucleus. Nat Neurosci 20:934942.

Campos CA, Bowen AJ, Roman CW, Palmiter RD (2018) Encoding of danger by parabrachial CGRP neurons. Nature 555:617-620.

Carter ME, Soden ME, Zweifel LS, Palmiter RD (2013) Genetic identification of a neural circuit that suppresses appetite. Nature 503: 111-114.

Carter ME, Han S, Palmiter RD (2015) Parabrachial calcitonin generelated peptide neurons mediate conditioned taste aversion. J Neurosci 35:4582-4586.

Chambers AP, Sandoval DA, Seeley RJ (2013) Integration of satiety signals by the central nervous system. Curr Biol 23:R379-R388.

Chen TW, Wardill TJ, Sun Y, Pulver SR, Renninger SL, Baohan A, Schreiter ER, Kerr RA, Orger MB, Jayaraman V, Looger LL, Svoboda K, Kim DS (2013) Ultrasensitive fluorescent proteins for imaging neuronal activity. Nature 499:295-300.

D’Agostino G, Lyons DJ, Cristiano C, Burke LK, Madara JC, Campbell JN, Garcia AP, Land BB, Lowell BB, Dileone RJ, Heisler LK (2016) Appetite controlled by a cholecystokinin nucleus of the solitary tract to hypothalamus neurocircuit. Elife 5:e12225.
Faroogi IS, O'Rahilly S (2008) Mutations in ligands and receptors of the leptin-melanocortin pathway that lead to obesity. Nat Clin Pract Endocrinol Metab 4:569-577.

Fenselau H, Campbell JN, Verstegen AMJ, Madara JC, Xu J, Shah BP, Resch JM, Yang Z, Mandelblat-Cerf Y, Livneh Y, Lowell BB (2017) A rapidly acting glutamatergic $A R C \rightarrow P V H$ satiety circuit postsynaptically regulated by $\alpha-\mathrm{MSH}$. Nat Neurosci 20:42-51.

Garfield AS, Li C, Madara JC, Shah BP, Webber E, Steger JS, Campbell JN, Gavrilova O, Lee CE, Olson DP, Elmquist JK, Tannous BA, Krashes MJ, Lowell BB (2015) A neural basis for melanocortin-4 receptor-regulated appetite. Nat Neurosci 18:863871.

Gaub S, Fisher SE, Ehret G (2016) Ultrasonic vocalizations of adult male Foxp2 -mutant mice: behavioral contexts of arousal and emotion. Genes Brain Behav 15:243-259.

Geerling JC, Stein MK, Miller RL, Shin J-W, Gray PA, Loewy AD (2011) FoxP2 expression defines dorsolateral pontine neurons activated by sodium deprivation. Brain Res 1375:19-27.

Ghosh KK, Burns LD, Cocker ED, Nimmerjahn A, Ziv Y, Gamal AE, Schnitzer MJ (2011) Miniaturized integration of a fluorescence microscope. Nat Methods 8:871-878.

Gribble FM, Reimann F (2016) Enteroendocrine cells: chemosensors in the intestinal epithelium. Annu Rev Physiol 78:277-299.

Grill HJ, Hayes MR (2009) The nucleus tractus solitarius: a portal for visceral afferent signal processing, energy status assessment and integration of their combined effects on food intake. Int $\mathrm{J}$ Obes 33:S11-S15.

Han S, Soleiman M, Soden M, Zweifel L, Palmiter RD (2015) Elucidating an affective pain circuit that creates a threat memory. Cell 162:363-374

Jennings JH, Sparta DR, Stamatakis AM, Ung RL, Pleil KE, Kash TL, Stuber GD (2013) Distinct extended amygdala circuits for divergent motivational states. Nature 496:224-228.

Kaelberer MM, Buchanan KL, Klein ME, Barth BB, Montoya MM, Shen X, Bohórquez DV (2018) A gut-brain neural circuit for nutrient sensory transduction. Science 361:eaat5236.

Krashes MJ, Koda S, Ye C, Rogan SC, Adams AC, Cusher DS, Maratos-Flier E, Roth BL, Lowell BB (2011) Rapid, reversible activation of AgRP neurons drives feeding behavior in mice. J Clin Invest 121:1424-1428.

Kreisler AD, Davis EA, Rinaman L (2014) Differential activation of chemically identified neurons in the caudal nucleus of the solitary tract in non-entrained rats after intake of satiating vs. non-satiating meals. Physiol Behav 136:47-54.

Li MM, Madara JC, Steger JS, Krashes MJ, Balthasar N, Campbell JN, Resch JM, Conley NJ, Garfield AS, Lowell BB (2019) The paraventricular hypothalamus regulates satiety and prevents obesity via two genetically distinct circuits. Neuron 102:653-667.e6.

Livneh Y, Ramesh RN, Burgess CR, Levandowski KM, Madara JC, Fenselau H, Goldey GJ, Diaz VE, Jikomes N, Resch JM, Lowell BB, Andermann ML (2017) Homeostatic circuits selectively gate food cue responses in insular cortex. Nature 546:611-616.

Lopes G, Bonacchi N, FrazÃ£O J, Neto JP, Atallah BV, Soares S, Moreira L, Matias S, Itskov PM, Correia PA, Medina RE, Calcaterra L, Dreosti E, Paton JJ, Kampff AR (2015) Bonsai: an event-based framework for processing and controlling data streams. Front Neuroinform 9:7.

Rinaman L (2010) Ascending projections from the caudal visceral nucleus of the solitary tract to brain regions involved in food intake and energy expenditure. Brain Res 1350:18-34.

Rodriguez E, Sakurai K, Xu J, Chen Y, Toda K, Zhao S, Han BX, Ryu $D$, Yin H, Liedtke W, Wang F (2017) A craniofacial-specific monosynaptic circuit enables heightened affective pain. Nat Neurosci 20:1734-1743.

Röhn TA (2011) A virus-like particle-based anti-nerve growth factor vaccine reduces inflammatory hyperalgesia: potential long-term therapy for chronic pain. J Immunol 186:1769-1780. 
Roman CW, Derkach VA, Palmiter RD (2016) Genetically and functionally defined NTS to PBN brain circuits mediating anorexia. Nat Commun 7:11905.

Roman CW, Sloat SR, Palmiter RD (2017) A tale of two circuits: CCKNTS neuron stimulation controls appetite and induces opposing motivational states by projections to distinct brain regions. Neuroscience 358:316-324.

Ryan PJ, Ross SI, Campos CA, Derkach VA, Palmiter RD (2017) Oxytocin-receptor-expressing neurons in the parabrachial nucleus regulate fluid intake. Nat Neurosci 20:1722-1733.

Sakurai K, Zhao S, Takatoh J, Rodriguez E, Lu J, Leavitt AD, Fu M, Han BX, Wang F (2016) Capturing and manipulating activated neuronal ensembles with CANE delineates a hypothalamic socialfear circuit. Neuron 92:739-753.

Shah BP, Vong L, Olson DP, Koda S, Krashes MJ, Ye C, Yang Z, Fuller PM, Elmquist JK, Lowell BB (2014) MC4R-expressing glutamatergic neurons in the paraventricular hypothalamus regulate feeding and are synaptically connected to the parabrachial nucleus. Proc Natl Acad Sci USA 111:13193-13198.

Stamatakis AM, Stuber GD (2012) Activation of lateral habenula inputs to the ventral midbrain promotes behavioral avoidance. Nat Neurosci 15:1105-1107.
Stanek E, Rodriguez E, Zhao S, Han BX, Wang F (2016) Supratrigeminal bilaterally projecting neurons maintain basal tone and enable bilateral phasic activation of jaw-closing muscles. J Neurosci 36:7663-7675.

Sternson SM, Eiselt AK (2017) Three pillars for the neural control of appetite. Annu Rev Physiol 79:401-423.

Sternson SM, Atasoy D, Betley JN, Henry FE, Xu S (2016) An emerging technology framework for the neurobiology of appetite. Cell Metab 23:234-253.

Trapp S, Cork SC (2015) PPG neurons of the lower brain stem and their role in brain GLP-1 receptor activation. Am J Physiol Integr Comp Physiol 309:R795-R804.

Travagli RA, Anselmi L (2016) Vagal neurocircuitry and its influence on gastric motility. Nat Rev Gastroenterol Hepatol 13:389 401.

Williams EK, Chang RB, Strochlic DE, Umans BD, Lowell BB, Liberles SD (2016) Sensory neurons that detect stretch and nutrients in the digestive system. Cell 166:209-221.

Zhang Y, Zhao S, Rodriguez E, Takatoh J, Han BX, Zhou X, Wang F (2015) Identifying local and descending inputs for primary sensory neurons. J Clin Invest 125:3782-3794. 